\title{
Adsorption of chlorophenols from aqueous solution over amino-modified ordered nanoporous silica materials
}

\author{
Arezoo Ghaffari • Mohammad Saber Tehrani • \\ Syed Waqif Husain - Mansoor Anbia • \\ Parviz Aberoomand Azar
}

Received: 27 April 2014/Accepted: 10 June 2014/Published online: 25 June 2014

(C) The Author(s) 2014. This article is published with open access at Springerlink.com

\begin{abstract}
The capability of the adsorption of 2-chlorophenol (2-CPh) and 2,4-dichlorophenol (2,4-DCPh) from aqueous solutions with mesoporous silica material MCM48 after functionalizing with amine groups, such as 3-(trimethoxysilyl)propyl amine and tetraethylenepentamine, was investigated in this study. It was found that amino-modified ordered mesoporous silica materials show significant adsorption for 2-CPh and 2,4-DCPh. This is possible due to the alkaline and acid interactions among the amine functional groups and chlorophenols. The adsorbents were characterized by X-ray diffraction, nitrogen adsorption-desorption isotherms and Fourier transform infrared. Batch adsorption studies were done to study the effect of various parameters like chemical modification, $\mathrm{pH}$, contact time, adsorbent dose and initial concentration. It was found that adsorption of 2-CPh and 2,4-DCPh depends upon the solution $\mathrm{pH}$. Adsorption data were modeled with the Langmuir and Freundlich adsorption isotherms. The data fitted the Freundlich isotherm model better than Langmuir. The kinetics analysis revealed that the overall adsorption process was successfully fitted with the pseudo-first-order kinetic model.
\end{abstract}

Keywords Nanoporous silica adsorbent .

Tetraethylenpentamine $\cdot 3$-(Trimethoxysilyl)propyl amine . Chlorophenols $\cdot$ Adsorption isotherm

A. Ghaffari · M. S. Tehrani ( $₫) \cdot$ S. W. Husain · P. A. Azar Department of Chemistry, Science and Research Branch, Islamic Azad University, Tehran, Iran

e-mail: drmsabertehrani@yahoo.com

M. Anbia

Research Laboratory of Nanoporous Materials, Faculty of Chemistry, Iran University of Science and Technology, Farjam Street, Narmak, 16846 Tehran, Iran

\section{Introduction}

The rapid increase of organic wastes from various industries and other sources over the past several decades has led organic pollutants to be widely distributed in the hydrosphere. Chlorophenol represent an important class of environmental water pollutants. [1] Many of these compounds are normally used in herbicides [2], insecticides [3], wood preservatives and industries as synthesis intermediates or as raw materials in the manufacturing of pharmaceuticals and dyes [4]. The presence of phenolic compounds in wastewater is a very important issue because of their toxicity and threat to the environment and human life. Chlorophenols cause not only the taste and odor problems even at concentrations below $0.1 \mu \mathrm{g} \mathrm{L}^{-1}$ [5], but also severe adverse effects such as toxicity, carcinogenicity $[6,7]$ and degradation of the water quality for consumptive use. Various processes were developed to treat the phenol-containing effluents including catalytic oxidation [8], biodegradation [9], solvent extraction [10] and adsorption [11]. Among these methods, adsorption is still the most versatile and widely used method, since it can remove many types of pollutants. Adsorption is an economical method for water decontamination applications and for separation in analytical purposes, and it is frequently used for the removal of phenolic pollutants [12]. Different adsorbents such as activated carbon [13, 14], zeolites [15], clay [16, 17] and chitosan $[18,19]$ were investigated for the removal of phenol and phenolic pollutants from wastewater. Even if activated carbon, obtained from different carbonaceous materials such as wood, nutshells and fruit stones, peat, charcoal, lignite, bituminous coal, and petroleum coke, are the most widely used adsorbents, the relatively high 
cost, the poor mechanical strength and sorbent losses during regeneration, limit their use [20]. Therefore, it is important to develop effective adsorbents with short adsorption equilibrium times for the removal of toxic species from aqueous solutions. Recent studies have shown that mesoporous materials [21-25] can have improved recoverability, large adsorption capacity and good selectivity for the adsorption of toxic compounds from aqueous solutions. Mesoporous materials are a class of nanoporous materials that were discovered in 1992 by the Mobil oil researchers [26, 27]. These materials, in particular, MCM-41 and MCM-48, have attracted much research attention owing to their potential applications as catalysts, catalyst supports and adsorbents [28-34]. The nanoporous silica material offers a number of potential advantages as adsorbents including regular channel type structures, high surface area and larger pore diameter and volume. Their modification by functionalized molecules can lead to adsorbents with specific properties [35, 36]. Removal of harmful organics by mesoporous materials grafted with organic or metal complexes has drawn much attention [24, 37].

In this study, MCM-48 was prepared and functionalized with 3-(trimethoxysilyl)propyl amine (TMSPA) and tetraethylenepentamine (TEPA) by post-synthesis treatment. Actually, the presence of free electron pairs of amine group within modified mesoporous MCM-48 materials leads to the sorptive properties for weak acidic organic compounds in water. Accordingly, amine groups are effective for the adsorption of organic compounds due to their potential charge association or high adsorption energy. The textural properties and structural order of the mesoporous materials were studied by nitrogen adsorption and XRD. The presence of amino functional groups on the surface of mesoporous silica was confirmed by means of FTIR analysis. The present work deals with the adsorption of 2-chlorophenol (2$\mathrm{CPh})$ and 2,4-dichlorophenol (2,4-DCPh) from aqueous solutions on a new nanosorbent; mesoporous silica modified with 3-(trimethoxysilyl)propyl amine(MCM-48/ TMSPA) and mesoporous silica modified with tetraethylenepentamine (MCM-48/TEPA). It was found that these adsorbents show good adsorption for chlorophenols. The effects of various operating parameters such as effect of adsorbent dose, initial concentration of chlorophenols, the $\mathrm{pH}$ of the solution and contact time were thoroughly studied. The equilibrium data are fitted into Langmuir and Freundlich equations to determine the correlation between the isotherm models and experimental data. The experimental data were also analyzed using the kinetic constants and first- and second-order kinetic models were calculated.

\section{Experimental}

\section{Materials}

The reactants used in this study were tetraethyl orthosilicate (TEOS) as a silica source, cetyltrimethylammonium bromide (CTAB) as a surfactant, sodium hydroxide $(\mathrm{NaOH})$ and sodium fluoride $(\mathrm{NaF})$ for synthesis of mesoporous silica (MCM-48), tetraethylenepentamine and ethanol for functionalization of mesoporous silica (MCM48/TEPA); 3-(trimethoxysilyl)propyl amine and dry Toluene were used to prepare modified mesoporous silica (MCM-48/TMSPA). 2-Chlorophenol (2-CPh) and 2,4dichlorophenol (2,4-DCPh) were used as adsorbate. All chemicals were of analytical grade and obtained from Merck(Germany).

Synthesis of mesoporous silica (MCM-48)

MCM-48 was prepared according to the procedure described by Shao et al. [38]. In a representative synthesis, the MCM-48 was prepared as follows: $10 \mathrm{~mL}$ of tetraethyl orthosilicate was mixed with $50 \mathrm{~mL}$ of deionized water and the mixture was stirred for $45 \mathrm{~min}$ at $308 \mathrm{~K}$, then $0.9 \mathrm{~g}$ of sodium hydroxide and $0.19 \mathrm{~g}$ sodium fluoride were added into the mixture. After another $60 \mathrm{~min}, 10.61 \mathrm{~g}$ of cetyltrimethylammonium bromide was added to the mixture, and further stirring continued for another $60 \mathrm{~min}$. The mixture was heated for $24 \mathrm{~h}$ at $393 \mathrm{~K}$ in an autoclave under static conditions, and the final product was filtered, washed with deionized water and dried at $373 \mathrm{~K}$. The samples were then calcined in air for $4 \mathrm{~h}$ with increasing the temperature to $823 \mathrm{~K}$ at $1{ }^{\circ} \mathrm{C} / \mathrm{min}$ of the heating rate.

Synthesis of MCM-48 functionalized with 3-(trimethoxysilyl)propyl amine

The grafting modification method was employed in this study. In $70 \mathrm{~mL}$ of dry toluene, $0.1 \mathrm{~g}$ of MCM-48 was suspended and $2 \mathrm{~mL}$ of 3-(trimethoxysilyl)propyl amine was added under a dry nitrogen atmosphere. The mixture was then refluxed for $12 \mathrm{~h}$. The solid product was filtered, washed with dichloromethane and ethanol and was dried. It was then soxhlet extracted with mixture of ethanol and dichloromethane (1:1) to remove the silylating reagent residue and dried overnight at $70{ }^{\circ} \mathrm{C}$ under a vacuum and denoted as MCM-48/TMSPA.

Synthesis of MCM-48 functionalized with tetraethylenepentamine

In $50 \mathrm{~g}$ ethanol, $1 \mathrm{~g}$ of tetraethylenepentamine (TEPA) was dissolved under stirring for $40 \mathrm{~min}$ at room temperature 
and then $2 \mathrm{~g}$ mesoporous silica was added. After refluxing for $4 \mathrm{~h}$, the resulting mixture was evaporated at $80^{\circ} \mathrm{C}$. Finally, the products were dried in air for $1 \mathrm{~h}$ at $100{ }^{\circ} \mathrm{C}$ and denoted as MCM-48/TEPA.

\section{Characterization}

Nitrogen adsorption-desorption isotherms of the synthesized materials were measured on Micromeritics model ASAP 2010 sorptometer. Surface area of the material was measured by Brunaure-Emmet-Teller (BET) method. The X-ray diffraction (XRD) patterns were recorded on a Philips 1830 diffractometer using $\mathrm{Cu}-\mathrm{K} \alpha$ radiation. The diffractograms were recorded in the $2 \theta$ range of $1-10$ with a $2 \theta$ step size of $0.01^{\circ}$. The Fourier transform infrared spectra (FT-IR) for the materials were measured on a DIGILAB FTS 7000 instrument under attenuated total reflection mode.

\section{Adsorption procedure}

Adsorption behavior was studied by a batch method, which permits convenient evaluation of parameters that influence the adsorption process such as contact time, chemical modification, initial concentration, adsorbent dose and solution pH. A series of aqueous solutions of chlorophenols with the same $\mathrm{pH}$ and their concentration ranging from 50 to $500 \mathrm{mg} \mathrm{L}^{-1}$ were prepared by dissolving pure analytes in double-distilled water. In each adsorption experiment, $0.01 \mathrm{~g}$ adsorbent was added to $25 \mathrm{~mL}$ chlorophenols solutions. The solutions were stirred constantly to observe the effect of $\mathrm{pH}$; chlorophenols with the same initial concentration were adjusted to different $\mathrm{pH}$ (3-10) using $0.1 \mathrm{~mol} \mathrm{~L}^{-1} \mathrm{NaOH}$ or $0.1 \mathrm{~mol} \mathrm{~L}^{-1} \mathrm{HCl}$ solutions. The resulting mixture was continuously shaken in a shaking bath with a speed of 200 shakes/min at $293 \mathrm{~K}$ for $3 \mathrm{~h}$ until equilibrium was reached. After adsorption, the residual concentration of chlorophenols (2-chlorophenol and 2,4dichlorophenol) in the filtrate was subsequently determined using the spectrophotometer at the wavelength corresponding to the maximum absorbance. In order to reduce the measurement errors, the UV absorption intensity for each equilibrium solution was measured in triplicates and the average value was used to calculate the equilibrium concentration; based on a standard calibration curve whose correlation coefficient square $\left(r^{2}\right)$ was 0.99 . The amount of chlorophenols adsorbed per unit mass of the $q_{\mathrm{e}}\left(\mathrm{mg} \mathrm{g}^{-1}\right)$ was calculated by the following equation:

$q_{\mathrm{e}}=\frac{\left(C_{0}-C_{\mathrm{e}}\right) V}{W}$

where $q_{\mathrm{e}}$ is the adsorption capacity $\left(\mathrm{mg} \mathrm{g}^{-1}\right)$ of the adsorbent at equilibrium; $C_{\mathrm{e}}$ and $C_{0}$ are the equilibrium and the initial concentrations of solute $\left(\mathrm{mg} \mathrm{L}^{-1}\right)$, respectively; $V$ is the volume of the solution (L), and $W$ is the mass $(\mathrm{g})$ of adsorbent used in the experiments.

Adsorption kinetics of chlorophenols

For the adsorption kinetics measurement of chlorophenols onto adsorbent, $25 \mathrm{~mL}$ of the chlorophenol solution with an initial concentration of $500 \mathrm{mg} \mathrm{L}^{-1}$ was transferred into a flask and mixed with $0.01 \mathrm{~g}$ of amino-modified ordered mesoporous silica materials. Samples were taken from the solution by filtration at different time intervals. The concentration of chlorophenol in the residual solution was determined and the amount of adsorption $\left(q_{t}\right)$ was calculated according to Eq. (2).

$q_{t}=\frac{\left(C_{0}-C_{t}\right) V}{W}$,

where $q_{t}$ is the amount of adsorption at time $t, C_{0}$ is the initial concentration of chlorophenol in the solution, $C_{t}$ is the concentration of chlorophenol in the solution at time $t$, $V$ is the volume of the solution, and $m$ is the mass of aminomodified ordered mesoporous silica materials (MCM-48/ TMSPA or MCM-48/TEPA).

\section{Results and discussion}

Physical and chemical properties of the adsorbents

$\mathrm{N}_{2}$ adsorption-desorption measurements indicate that amino-modified ordered mesoporous silica materials possess good mesopore structure ordering and a relatively narrow pore size distribution. In addition, modified MCM48 materials have a lower BET surface area compared to MCM-48 materials (Fig. 1). Different BET surface areas are a result of the different pore volumes. The lower values

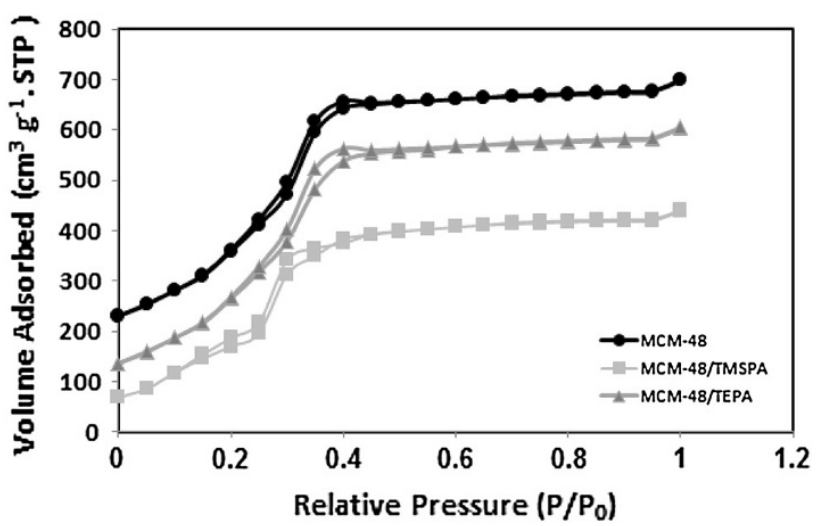

Fig. 1 Adsorption-desorption isotherms of nitrogen at $77 \mathrm{~K}$ over MCM-48, MCM-48/TMSPA and MCM-48/TEPA 
Table 1 Textural properties determined from nitrogen adsorptiondesorption experiments at $77 \mathrm{~K}$

\begin{tabular}{llcl}
\hline Adsorbent & $d$ spacing $(\mathrm{nm})$ & $A_{\text {BET }}\left(\mathrm{m}^{2} \mathrm{~g}^{-1}\right)$ & $V_{\mathrm{p}}\left(\mathrm{cm}^{3} \mathrm{~g}^{-1}\right)$ \\
\hline MCM-48 & 3.1 & $1,312.6$ & 1.22 \\
MCM-48/TMSPA & 2.6 & 574.8 & 0.65 \\
MCM-48/TEPA & 2.4 & 528.3 & 0.53 \\
\hline
\end{tabular}

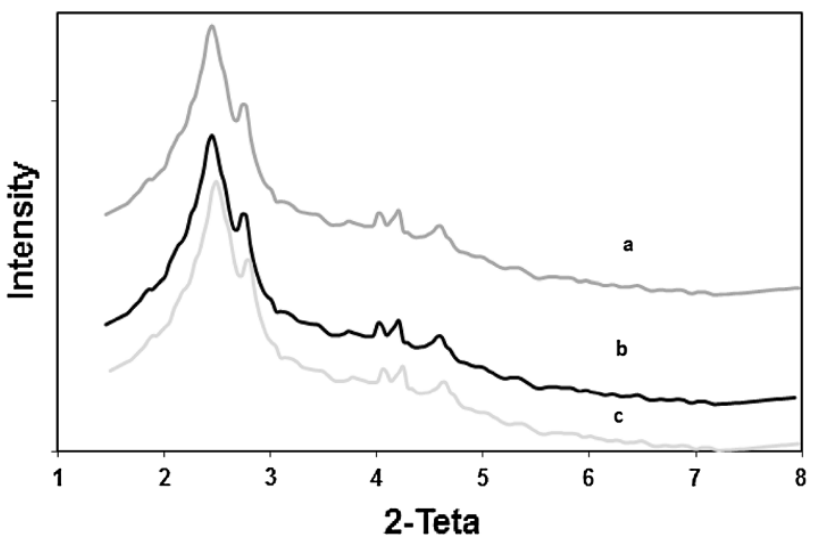

Fig. 2 XRD patterns of MCM-48 (a), MCM-48/TEPA (b) MCM-48/ TMSPA (c)

of composite compared with pure MCM-48 are mainly attributed to the presence of the dense amine group.

From the nitrogen sorption isotherms of mesoporous silica before and after modification, it can be seen that their isotherms are similar to the shape of type IV [39]. Table 1 shows textural properties of modified and calcined MCM48 mesoporous materials including BET surface area, average pore diameter and pore volume. Large pore diameter and pore volume and high surface area of the samples indicate that the samples have mesoporous structure.

In order to check the structural degradation, XRD data of MCM-48 and amino-functionalized mesoporous silica materials were obtained on diffractometer using $\mathrm{Cu}-\mathrm{K} \alpha$ radiation of wavelength $0.154 \mathrm{~nm}$. Figure 2 shows the XRD peaks of the samples. The XRD patterns of MCM- 48 exhibit two peaks at $2 \theta$ smaller than $3^{\circ}$ and a series of weak peaks in the range $3.5-5.5^{\circ}$ as expected for MCM-48 phase. They are assigned to the (2 11 1), (2 20$),(420)$, (3 3 $2)$, and $\left(\begin{array}{lll}4 & 2 & 2\end{array}\right)$ reflections in the $\mathrm{Ia}_{3} \mathrm{~d}$ space group. The peaks obtained in this study for MCM-48/TMSPA and MCM-48/TEPA highly match with the similar peaks reported in Refs. [40, 41].

Qualitative identification of functional groups was accomplished by FT-IR spectroscopy. Figure 3 shows the FT-IR spectrum of unfunctionalized and amino-functionalized MCM-48 materials over the range of $4,000-400 \mathrm{~cm}^{-1}$. A broad band in the range of $3,700-3,037 \mathrm{~cm}^{-1}$ is seen which

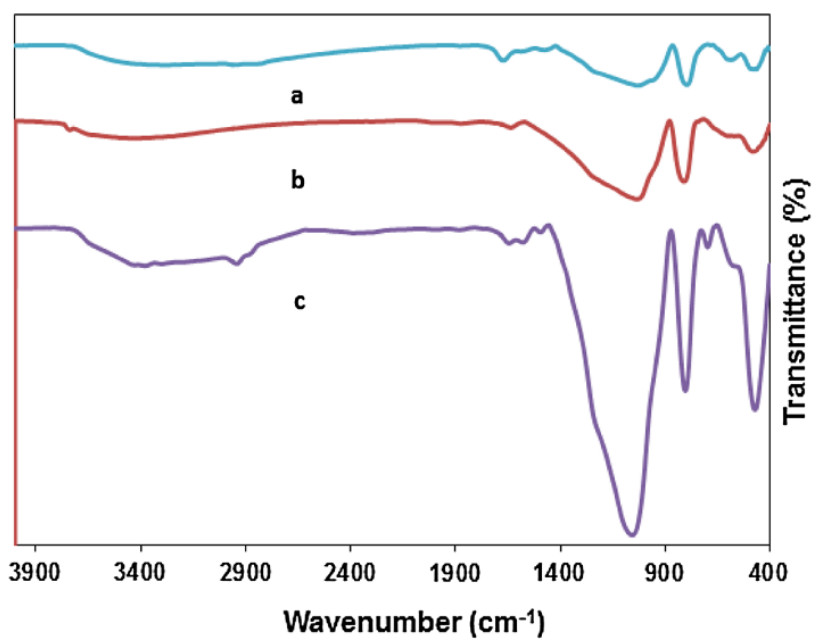

Fig. 3 FTIR spectra of MCM-48/TEPA (a), MCM-48 (b), MCM-48/ TMSPA(c)

can be attributed to the framework of $\mathrm{Si}-\mathrm{OH}$ group interaction with the defect sites and adsorbed water molecules. The $\mathrm{Si}-\mathrm{OH}$ peak appears at about $3,409 \mathrm{~cm}^{-1}$, while peaks for the weak single $\mathrm{Si}-\mathrm{OH}$ groups derived from the germinal $\mathrm{Si}-\mathrm{OH}$ groups were observed at $3,708 \mathrm{~cm}^{-1}$. The asymmetric stretching vibrations of $\mathrm{Si}-\mathrm{O}-\mathrm{Si}$ and $\mathrm{Si}-\mathrm{OH}$ are observed by the absorption bands at $900-1,529 \mathrm{~cm}^{-1}$ and the band at $790.68 \mathrm{~cm}^{-1}$ is assigned to free silica. In general, the functionalized silica with amino groups show a broad $\mathrm{NH}_{2}$ symmetric and asymmetric stretching vibrations at 3,050$3,650 \mathrm{~cm}^{-1}$, an $\mathrm{N}-\mathrm{H}$ deformation peak at $1,625-1,434 \mathrm{~cm}^{-1}$, $\mathrm{C}-\mathrm{H}$ stretching of methyl groups at 3,000-2,850 and $1,467 \mathrm{~cm}^{-1}$. In addition, in comparison with the MCM-48/ TEPA, the amino bands are weaker for MCM-48/TMSPA.

Adsorption studies

\section{Effect of chemical modification}

In general, the adsorption capacity depends on the chemical and physical properties of the surface of adsorbent. It is clear from the Fig. 4 that the MCM-48 modified by amines group possessed the higher adsorption capacity towards $2-\mathrm{CPh}$ and 2,4-DCPh than the MCM-48. The order of adsorption in terms of the amount adsorbed ( $\mathrm{mg} \mathrm{g}^{-1}$ adsorbent) on the adsorbents is MCM-48/TMSPA > MCM-48/TEPA > MCM-48.

The pure silica surface does not provide strong adsorption sites to interact strongly with chlorophenols (167 and $155 \mathrm{mg} \mathrm{g}^{-1}$ for 2,4-DCPh and 2-CPh, respectively). The maximum adsorption capacity of chlorophenols by mesoporous silica was enhanced through functionalization with amine groups $\left(300,350 \mathrm{mg} \mathrm{g}^{-1}\right.$ for 2-CPh on MCM-48/ TEPA and MCM-48/TMSPA, respectively and 315, 
Fig. 4 Adsorption isotherm for 2-CPh and 2,4-DCPh removal on synthesis adsorbents (contact time $=3 \mathrm{~h}$, adsorbent dosage $=0.4 \mathrm{~g} \mathrm{~L}^{-1}$ )

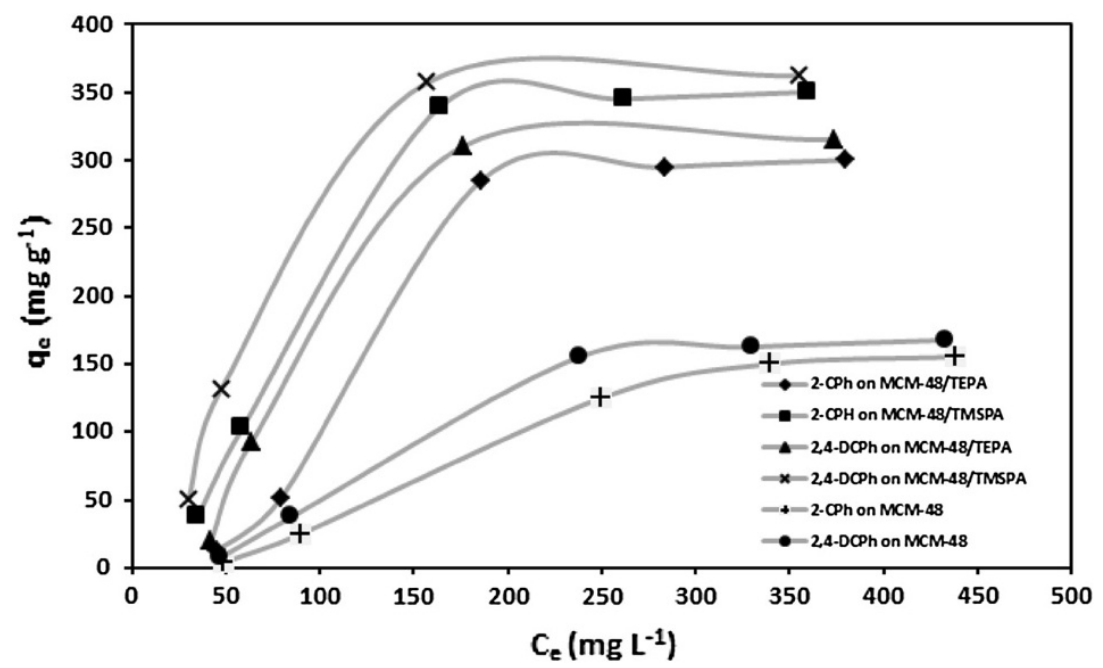

$362 \mathrm{mg} \mathrm{g}^{-1}$ for 2,4-DCPh on MCM-48/TEPA and MCM48/TMSPA, respectively). The higher adsorption capacity of mesoporous silica materials functionalized with amine may be explained to proceed via electrostatic interaction between the surface of adsorbent and chlorophenol; also this may be because of the hydrophobicity created by amine groups. It is also surmised that the presence of a free electron pair causes more interaction between chlorophenols and adsorbent in modified MCM-48. In other words, chlorophenols are weak acids and there are acid and alkaline interactions among amine groups and chlorophenols. For comparison, the adsorption capacities for chlorophenol showed by different common adsorbents were as follows: $13.83 \mathrm{mg} \mathrm{g}^{-1}$ for 2-CPh and $19.61 \mathrm{mg} \mathrm{g}^{-1}$ for 2,4-DCPh (on $\mathrm{Pd} / \mathrm{Fe}$ nanoparticles with multi-walled carbon nanotube support) [42]; $3.86 \mathrm{mmol} \mathrm{g}^{-1}$ for 2,4$\mathrm{DCPh}$ (on activated carbon PSO) [14]; $70 \mathrm{mg} \mathrm{g}^{-1}$ for 2-CPh (on fuel oil fly ash) [43]; $285.71 \mathrm{mg} \mathrm{g}^{-1}$ for 2,4$\mathrm{DCPh}$ (on ammonia-modified activated carbon) [44]; $232.56 \mathrm{mg} \mathrm{g}^{-1}$ for 2,4-DCPh (on activated carbon derived from agricultural waste) [45]; $244 \mathrm{mg} \mathrm{g}^{-1}$ for 2,4-DCPh (on Mn-modified activated carbon prepared from Polygonum orientale Linn) [46]; $29.58 \mathrm{mg} \mathrm{g}^{-1}$ for 2,4-DCPh (on cyclodextrin-ionic liquid polymer as a macroporous material) [47]. It can be observed that the adsorption efficiency of amino-modified MCM-48 is higher than that of most adsorbents. We can state that the MCM-48/TEPA and MCM-48/TMSPA adsorbents are interesting candidates for applications in chlorophenol removal from wastewater.

\section{Effect of contact time and concentration on the adsorption procedure}

The influence of initial concentration on the removal of chlorophenols by MCM-48/TMSPA and MCM-48/TEPA adsorbents was studied at initial concentration of

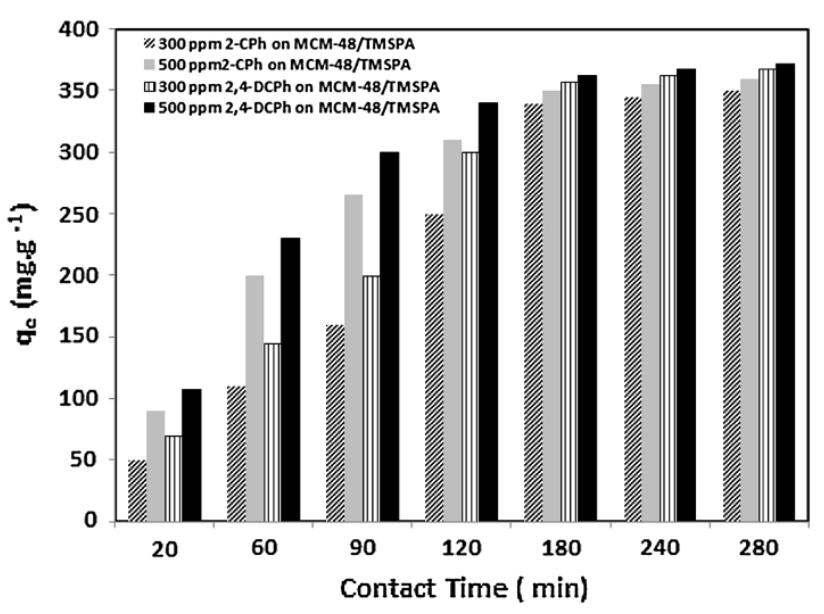

Fig. 5 Effect of initial concentration and contact time on removal of 2-CPh and 2,4-DCPh on MCM-48/TMSPA (adsorbent dosage $=0.4 \mathrm{~g} \mathrm{~L}^{-1}$, contact time $=3 \mathrm{~h}$ )

$50-500 \mathrm{mg} \mathrm{L}^{-1}$ and the result presented in Figs 5 and 6. Generally, it is obvious from the figures that the sorption capacity of chlorophenol on modified mesoporous silica increased with increase in chlorophenol concentration. The increase in adsorption capacity with increasing chlorophenol concentration could be due to the higher probability of collision between adsorbent surface and chlorophenol molecules. In addition, this observation might be attributed to the increase in the number of analyte molecules (or ions) competing for the available binding sites on the surface of the adsorbent.

Figures 5 and 6 show the effect of contact time for the adsorption of 2-CPh and 2,4-DCPh on functionalized MCM-48. It is obvious that time has significant influence on the adsorption of chlorophenol. Figures 5 and 6 also indicate that the time required for equilibrium is $3 \mathrm{~h}$ : adsorption equilibrium time, determined at 


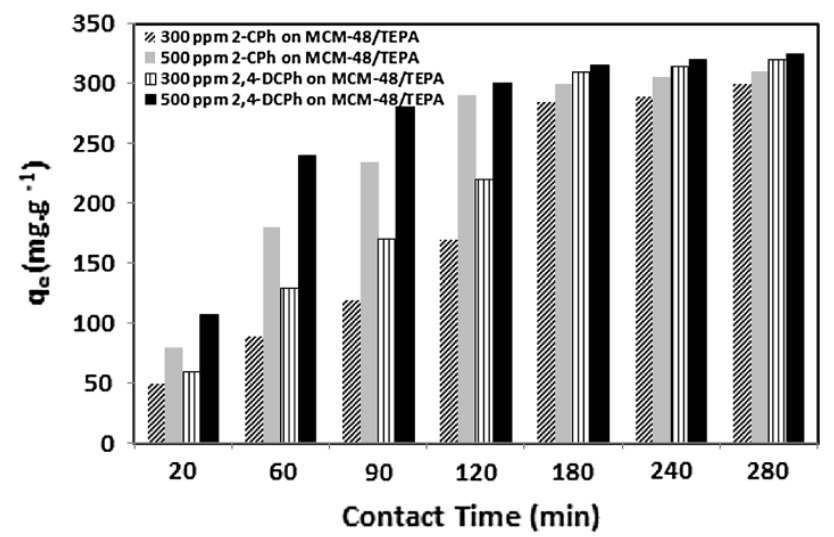

Fig. 6 Effect of initial concentration and contact time on removal of 2-CPh and 2,4-DCPh on MCM-48/TEPA (adsorbent dosage $=0.4 \mathrm{~g} \mathrm{~L}^{-1}$, contact time $=3 \mathrm{~h}$ )

the time after which the concentration of the chlorophenol solution remained without change during the adsorption process. Thus, for all equilibrium adsorption studies, the contact period was kept $3 \mathrm{~h}$. It is obvious from Figs. 5 and 6 that the extent of adsorption is rapid in the initial stages and becomes slow in the next stages until saturation is occurred. This is clear from the fact that a large number of surface sites are available for adsorption at the initial stages and after passing of time; the remaining surface sites are difficult to be occupied because of repulsion between bulk phases and the solute molecules of the solid. The mechanism of adsorption is an essentially diffusion of analyte molecules into pores of adsorbent surface.

\section{Effect of $\mathrm{pH}$}

One of the most important factors which affect the adsorption of analyte from aqueous solution is the $\mathrm{pH}$. This is because it plays an important role in the adsorption process as the $\mathrm{OH}^{-}$and $\mathrm{H}^{+}$ions might compete with the other analyte for the adsorption on the active site and/or a strong water hydration sphere around the analyte molecule. The effect of the $\mathrm{pH}$ on the adsorption 2-CPh and 2,4$\mathrm{DCPh}$ from aqueous solution was studied at different $\mathrm{pHs}$ (from 3 to12) and the results are presented in Fig. 7. Hydrochloric acid and sodium hydroxide solutions were used to adjust the $\mathrm{pH}$ of the solution. At low $\mathrm{pH}$, the adsorption of the 2-CPh and 2,4-DCPh was considerably low and this may be due to the fact that $\mathrm{H}^{+}$, which have almost the same concentration $\left(1 \times 10^{-4} \mathrm{M}\right)$ out-compete with the chlorophenol for the same active sites [48, 49]. Meanwhile, when the $\mathrm{pH}$ of the solution was increased the adsorption was greatly enhanced; most of the chlorophenol

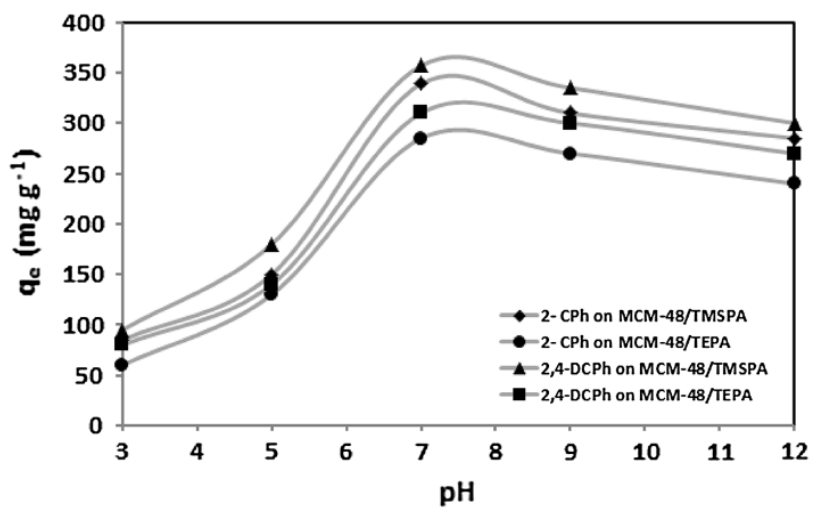

Fig. 7 Effect of $\mathrm{pH}$ on removal of chlorophenols on MCM-48/ TMSPA and MCM-48/TEPA (initial concentration $=300 \mathrm{mg} \mathrm{L}^{-1}$, adsorbent dose $0.4 \mathrm{~g} \mathrm{~L}^{-1}$, contact time $=3 \mathrm{~h}$ )

molecules were present in their ionized; negative ions form. This leads to the increase in the adsorption. But in the high $\mathrm{pH}(9-12)$ the adsorption capacity was decreased. This decrease was mostly due to the repulsion between the modified mesoporous silica and the anionic chlorophenol ions as well as the competition between the analytes and the hydroxyl ions present (higher in concentration than the chlorphenol), to the solution at such high $\mathrm{pH}$, for the adsorption on the modified MCM- 48 active sites.

\section{Effect of adsorbents' dose}

The determination of optimum dose is essential for optimization of the removal process. It is observed that with a slight increase of the dose of the modified MCM- 48 for a fixed initial chlorophenol concentration the adsorption capacity increases (Fig. 8). This can be attributed to the availability of more adsorption sites and increased adsorbent surface area due to the increased adsorbent. It can be concluded that the rate of phenolic compounds binding with adsorbents increases more rapidly in the initial stages and after some point adsorption is marginal and becomes almost a constant. Therefore, the optimum adsorbent dosage was taken as $0.01 \mathrm{~g} / 25 \mathrm{~mL}$ for further experiments.

\section{Adsorption isotherms}

The equilibrium studies are very important in understanding the adsorption mechanism and in designing the adsorption process. The experimental equilibrium data are fitted with different isotherms to find the most suitable model that can be used for designing and assessing the performance of the adsorption process. The parameters obtained from different isotherm models provide important 
information on the adsorption mechanism, the surface properties of the sorbent and the affinities between the sorbent and sorbate. In this study, the experimental data were fitted with Langmuir and Freundlich isotherms. Langmuir isotherm assumes the ideal situation of an entirely homogeneous surface of the sorbent, the monolayer coverage of the adsorption surface, no interactions between the adsorbed molecules and the heat of adsorption is dependent on surface coverage [50].

The Langmuir isotherm is represented by the equation [51]

$\frac{C_{\mathrm{e}}}{q_{\mathrm{e}}}=\frac{1}{q_{\mathrm{m}} b}+\frac{1}{q_{\mathrm{m}}} C_{\mathrm{e}}$,

where $q_{\mathrm{e}}$ is the adsorbed amount of chlorophenol under equilibrium ( $\left.\mathrm{mg} \mathrm{g}^{-1}\right), C_{\mathrm{e}}$ is the equilibrium concentration of chlorophenol in solution $\left(\mathrm{mg} \mathrm{L}^{-1}\right), q_{\mathrm{m}}$ is the monolayer adsorption capacity $\left(\mathrm{mg} \mathrm{g}^{-1}\right)$ and $b\left(\mathrm{~L} \mathrm{mg}^{-1}\right)$ is the constant related to the free energy of adsorption. Freundlich isotherm is an empirical model, appropriate for adsorption on heterogeneous surfaces, with interaction between adsorbed molecules [52]. Freundlich isotherm is expressed as follows [53]:

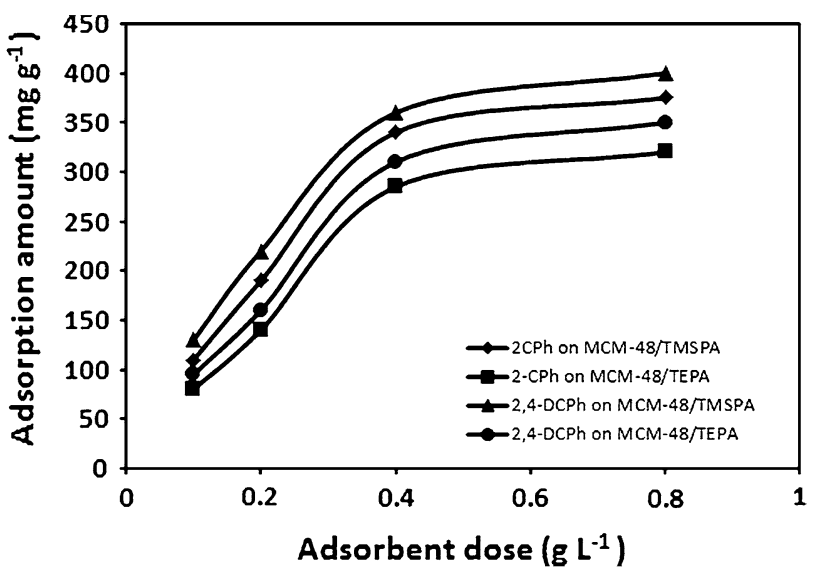

Fig. 8 Effect of adsorbent dose on removal of chlorophenols on MCM-48/TMSPA and MCM-48/TEPA (initial concentration $=300 \mathrm{mg} \mathrm{L}^{-1}$, contact time $=3 \mathrm{~h}$ ) $\ln q_{\mathrm{e}}=\ln K_{\mathrm{F}}+\left(\frac{1}{n}\right) \ln C_{\mathrm{e}}$

where $K_{\mathrm{F}}$ is the Freundlich isotherm constant concerned with the relative adsorption capacity and $n$ is constant related to the intensity of adsorption. By plotting of $\ln q_{\mathrm{e}}$ versus $\ln C_{\mathrm{e}}$ the value of $K_{\mathrm{F}}$ was obtained from the intercept and $n$ from the slope. The slope and the intercept correspond to $(1 / n)$ and $K_{\mathrm{F}}$, respectively.

The correlation coefficient $\left(R^{2}\right)$ and the parameters of isotherms are listed in Table 2 for 2-CPh and 2,4-DCPh.

It can be seen that Freundlich isotherm fits the data better than Langmuir isotherm. The MCM-48/TMSPA and MCM-48/TEPA adsorbents used in this work had a relatively large adsorption capacity. This indicates that modified MCM-48 materials are effective to remove 2-CPh and 2,4-DCPh from aqueous solutions.

\section{Adsorption kinetics}

The adsorption kinetic of 2-CPh and 2,4-DCPh on MCM48/TMSPA and MCM-48/TEPA adsorbents was investigated by fitting the experimental data with two kinetic models, namely pseudo-first-order and pseudo-secondorder. The linearized form of the pseudo-first-order equation [54] is generally expressed as

$\ln \left(q_{\mathrm{e}}-q_{t}\right)=\ln q_{\mathrm{e}}-k_{1} t$,

where $q_{\mathrm{e}}$ and $q_{t}$ are amounts of chlorophenol adsorbed $\left(\mathrm{mg} \mathrm{g}^{-1}\right)$ at equilibrium and time $t(\mathrm{~min})$, respectively, and $k_{1}$ is the rate constant of pseudo-first-order adsorption $\left(\mathrm{min}^{-1}\right)$. The values of $\log \left(q_{\mathrm{e}}-q_{t}\right)$ were calculated from the kinetic data of Figs. 9 and 10. The $k_{1}$ values and $q_{\mathrm{e}}$ were calculated from slope and intercept from the plots of $\log \left(q_{\mathrm{e}}-q_{t}\right)$ versus $t$ for different concentration. The $k_{1}$ values, $q_{\mathrm{e}}$ calculated and correlation coefficient is given in Table 3. Also, the calculated $q_{\mathrm{e}}$ values agree with the experimental data $\left(q_{\mathrm{e} . \exp }\right)$. These indicate that the adsorption perfectly complies with pseudo-first-order reaction.The linearized form of the pseudo-second-order equation is [55] as follows:

Table 2 Langmuir and Freundlich constants for adsorption 2-CPh and 2,4-DCPh by MCM-48/TEPA and MCM-48/TMSPA adsorbents

\begin{tabular}{|c|c|c|c|c|c|c|c|}
\hline \multirow[t]{2}{*}{ Adsorbate } & \multirow[t]{2}{*}{ Adsorbent } & \multicolumn{3}{|c|}{ Langmuir constants } & \multicolumn{3}{|c|}{ Freundlich constants } \\
\hline & & $q_{\mathrm{m}}\left(\mathrm{mg} \mathrm{g}^{-1}\right)$ & $b\left(\mathrm{~L} \mathrm{mg}^{-1}\right)$ & $R^{2}$ & $K_{\mathrm{F}}\left(\mathrm{mg} \mathrm{g}^{-1}\right)$ & $n\left(\mathrm{~L} \mathrm{mg}^{-1}\right)$ & $R^{2}$ \\
\hline \multirow[t]{2}{*}{$2-\mathrm{CPh}$} & MCM-48/TMSPA & 588.23 & 0.0052 & 0.879 & 0.33 & 0.73 & 0.9943 \\
\hline & MCM-48/TEPA & 555.55 & 0.0039 & 0.8268 & 0.003 & 0.455 & 0.9981 \\
\hline \multirow[t]{2}{*}{ 2,4-DCPh } & MCM-48/TMSPA & 476.19 & 0.01 & 0.9433 & 1.092 & 0.85 & 0.9908 \\
\hline & MCM-48/TEPA & 588.23 & 0.0040 & 0.8716 & 0.03 & 0.54 & 0.9947 \\
\hline
\end{tabular}




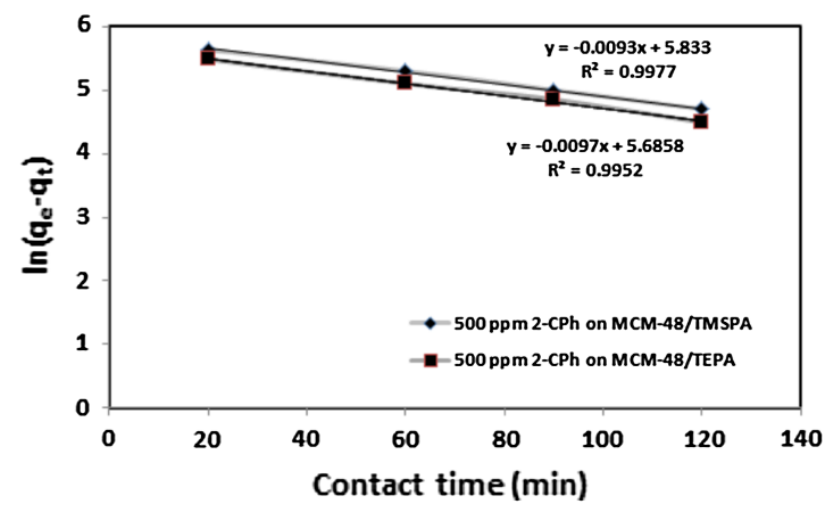

Fig. 9 Pseudo-first-order kinetics plots for the removal of 2-CPh by MCM-48/TEPA and MCM-48/TMSPA adsorbents (adsorbent dosage $=0.4 \mathrm{~g} \mathrm{~L}^{-1}$, contact time $=3 \mathrm{~h}$ )

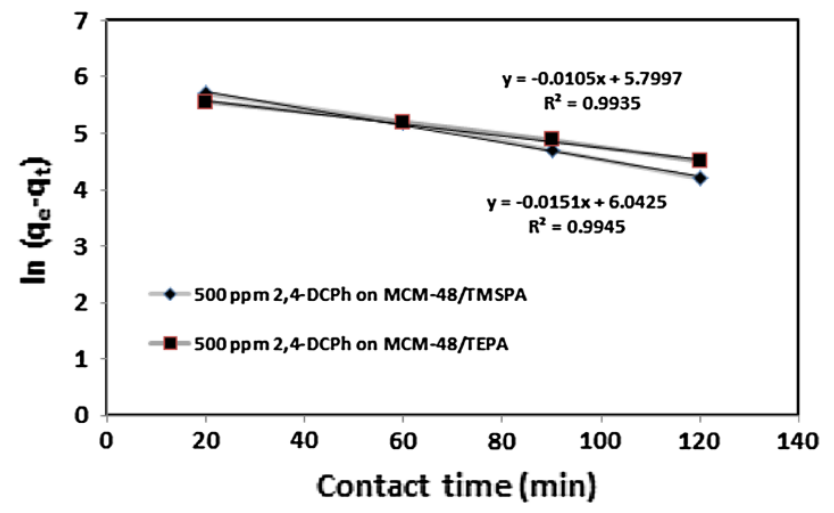

Fig. 10 Pseudo-first-order kinetics plots for the removal of 2,4-DCPh by MCM-48/TEPA and MCM-48/TMSPA adsorbents (adsorbent dosage $=0.4 \mathrm{~g} \mathrm{~L}^{-1}$, contact time $=3 \mathrm{~h}$ )

$\frac{t}{q_{t}}=\frac{1}{k_{2} q_{\mathrm{e}}^{2}}+\left(\frac{1}{q_{\mathrm{e}}}\right) t$

where $k_{2}$ is the rate constant of pseudo-second-order adsorption $\left[\mathrm{g}(\mathrm{mg} \mathrm{min})^{-1}\right]$. The plots of $\left(t / q_{t}\right)$ versus $t$ for the pseudo-second-order model given in Eq. (6) were drawn at a different solution in Figs. 11 and 12. The $q_{\mathrm{e}}$ and $k_{2}$ values were calculated from slope and intercept of these plots, respectively. The $q_{\text {e.exp }}$ values do not agree with calculated ones, obtained from the Eq. (6). These results show that the adsorption of chlorophenol onto mesoporous silica modified with TEPA and TMSPA is not a pseudosecond-order reaction.

Table 3 shows that the correlation coefficients of firstorder kinetic model are greater than second-order kinetic. Also, the calculated $q_{\mathrm{e}}$ values of first-order kinetic model agree with the experimental data $\left(q_{\text {e.exp }}\right)$.

\section{Conclusion}

In the present work, The adsorption of 2-chlorophenol and 2,4-dichlorophenol by MCM-48 ordered mesoporous silica, aminopropyl functionalized MCM-48 (MCM-48/TMSPA) and tetraethylenepentamine functionalized MCM-48 (MCM-48/TEPA) materials was studied. Many of the factors that greatly affect the adsorption process were studied and optimized such as the mass of adsorbent, analyte concentration, $\mathrm{pH}$ of the solution and contact time. The obtained results showed that the adsorption capacity of the adsorbents varied in the order MCM-48/TMSPA > MCM-48/ TEPA $>$ MCM-48. The adsorption capacity of chlorophenols by mesoporous silica was enhanced through functionalization with amine groups. This may be because of the hydrophobicity created by amine group. It is also surmised that the chlorophenols are weak acids and there are acid and alkaline interactions among amine groups of adsorbent and chlorophenols. Langmuir, Freundlich isotherm models are employed for modeling the adsorption behaviors of chlorophenols adsorption. It is observed that Freundlich isotherm is found to be the more suitable and appropriate

Table 3 Pseudo-first-order and pseudo-second-order constants for the removal 2-CPh and 2,4-DCPh by MCM-48/TEPA and MCM-48/TMSPA adsorbents

\begin{tabular}{|c|c|c|c|c|c|c|c|c|}
\hline \multirow[t]{2}{*}{ Adsorbate } & \multicolumn{2}{|c|}{ Adsorbent (500 ppm) } & \multicolumn{3}{|c|}{ Pseudo-first-order constants } & \multicolumn{3}{|c|}{ Pseudo-second-order constants } \\
\hline & & $\begin{array}{l}q_{\mathrm{e}, \exp } \\
\left(\mathrm{mg} \mathrm{g}^{-1}\right)\end{array}$ & $\begin{array}{l}q_{\mathrm{e}, \mathrm{cal}} \\
\left(\mathrm{mg} \mathrm{g}^{-1}\right)\end{array}$ & $\begin{array}{l}k_{1} \\
{\left[\mathrm{~g}(\mathrm{mg} \min )^{-1}\right]}\end{array}$ & $R^{2}$ & $\begin{array}{l}q_{\mathrm{e}, \mathrm{cal}} \\
\left(\mathrm{mg} \mathrm{g}^{-1}\right)\end{array}$ & $\begin{array}{l}k_{2} \\
{\left[\mathrm{~g}(\mathrm{mg} \min )^{-1}\right]}\end{array}$ & $R^{2}$ \\
\hline \multirow[t]{2}{*}{$2-\mathrm{CPh}$} & MCM-48/TMSPA & 350 & 341.38 & 0.0093 & 0.9977 & 666.6 & $7.75 \times 10^{-6}$ & 0.9211 \\
\hline & MCM-48/TEPA & 300 & 294.65 & 0.0097 & 0.9952 & 588.23 & $8.2 \times 10^{-6}$ & 0.9024 \\
\hline \multirow[t]{2}{*}{ 2,4-DCPh } & MCM-48/TMSPA & 362 & 420.94 & 0.0151 & $\begin{array}{l}0.9945 \\
0.9823\end{array}$ & 555.55 & $1.63 \times 10^{-5}$ & 0.9823 \\
\hline & MCM-48/TEPA & 315 & 330.2 & 0.0105 & $\begin{array}{l}0.9935 \\
0.9401\end{array}$ & 625 & $7.49 \times 10^{-6}$ & 0.9401 \\
\hline
\end{tabular}




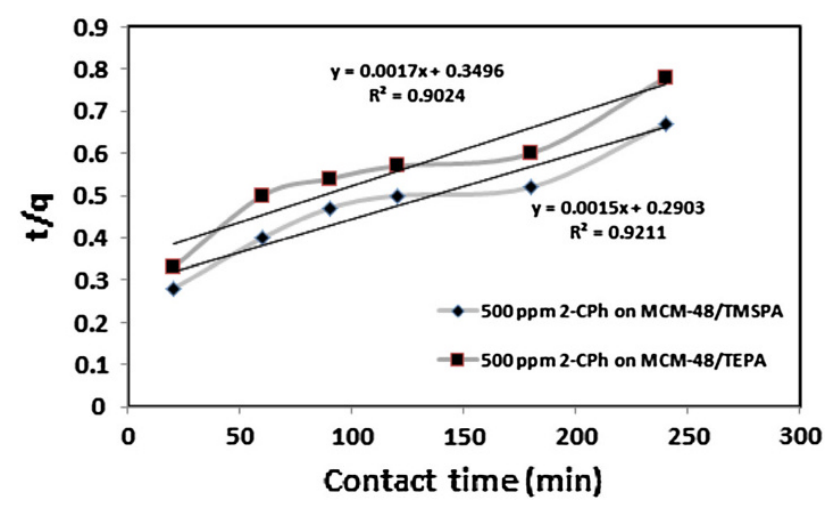

Fig. 11 Pseudo-second-order kinetics plots for the removal of 2-CPh by MCM-48/TEPA and MCM-48/TMSPA adsorbents (adsorbent dosage $=0.4 \mathrm{~g} \mathrm{~L}^{-1}$, contact time $=3 \mathrm{~h}$ )

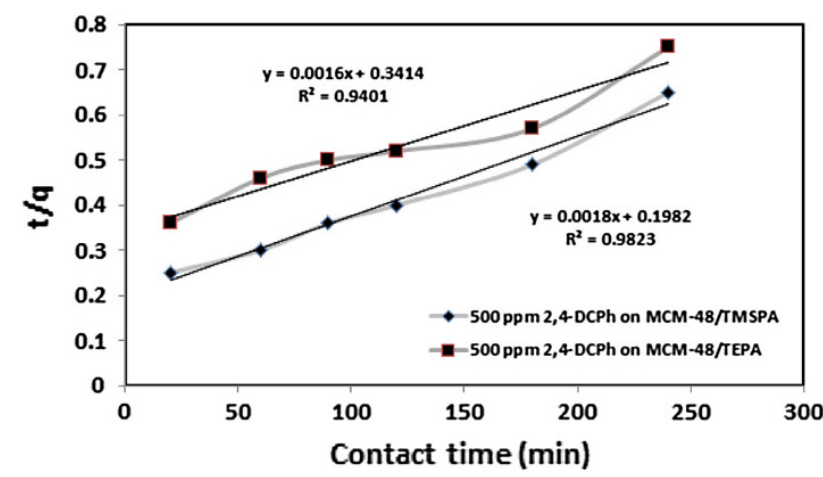

Fig. 12 Pseudo-second-order kinetics plots for the removal of 2,4DCPh by MCM-48/TEPA and MCM-48/TMSPA adsorbents (adsorbent dosage $=0.4 \mathrm{~g} \mathrm{~L}^{-1}$, contact time $=3 \mathrm{~h}$ )

model to explain the adsorption isotherm. The kinetic studies indicated that the adsorption of 2-CPh and 2,4$\mathrm{DCPh}$ onto modified adsorbents followed the pseudofirst-order model.

Acknowledgments $\mathrm{We}$ are grateful to appreciate to the Iran Nanotechnology Initiative Council for financing this work.

Open Access This article is distributed under the terms of the Creative Commons Attribution License which permits any use, distribution, and reproduction in any medium, provided the original author(s) and the source are credited.

\section{References}

1. Denzeli, A., Cihangir, N., Rad, A.Y., Taner, M., Alsancak, G.: Removal of chlorophenol from synthetic solutions using Phanerochate Chrysosporium. Process Biochem. 37, 2025-2030 (2004)

2. Tsyganok, A.I., Yamanaka, I., Otsuka, K.: Dechlorination of chloroaromatics by electrocatalytic reduction over palladium- loaded carbon felt at room temperature. Chemosphere 39, 1819-1831 (1999)

3. Dabo, P., Cyr, A., Laplante, F., Jean, F., Menard, H., Lessard, J.: Electrocatalytic dehydrochlorination of pentachlorophenol to phenol or cyclohexanol. Environ. Sci. Tech. 34, 1265-1268 (2000)

4. Pera-Titus, M., García-Molina, V., Baños, M.A., Giménez, J., Esplugas, S.: Degradation of chlorophenols by means of advanced oxidation processes: a general review. Appl. Catal. B Environ. 47, 219-256 (2004)

5. Verschueren, K.: Handbook of environmental data on organic chemicals. Wiley, New York (2001)

6. Huff, J.: Sawmill chemicals and carcinogenesis. Environ. Health Perspect. 109, 209-212 (2001)

7. Lampi, P., Hakulinen, T., Luostarinen, T., Pukkala, E., Teppo, L.: Cancer incidence following chlorophenol exposure in a community in southern Finland. Arch. Environ. Health. 47, 167-175 (1992)

8. Kumakiri, I., Hokstad, J., Peters, T.A., Melbye, A.G., Ræder, H.: Oxidation of aromatic components in water and seawater by a catalytic membrane process. J. Petrol. Sci. Eng. 79, 37-44 (2011)

9. Yan, J., Nanqi, R., Xun, C., Di, W., Liyan, Q., Sen, L.: Biodegradation of phenol and 4-chlorophenol by the mutant strain CTM. Chin. J. Chem. Eng. 16(5), 796-800 (2008)

10. Fan, J., Fan, Y., Pei, Y., Wu, K., Wang, J., Fan, M.: Solvent extraction of selected endocrine-disrupting phenols using ionic liquids. Sep. Purif. Technol. 61, 324-331 (2008)

11. Arana, J.M.R.R., Mazzoco, R.R.: Adsorption studies of methylene blue and phenol onto black stone cherries prepared by chemical activation. J. Hazard. Mater. 180, 656-661 (2010)

12. Hararah, M.A., Ibrahim, K.A., Al-Muhtaseb, A.H., Yousef, R.I., Abu-Surrah, A., Qatatsheh, A.: Removal of phenol from aqueous solutions by adsorption onto polymeric adsorbents. J. Appl. Polym. Sci. 117, 1908-1913 (2010)

13. Ioannou, Z., Simitzis, J.: Adsorption kinetics of phenol and 3 -nitrophenol from aqueous solutions on conventional and novel carbons. J. Hazard. Mater. 171, 954-964 (2009)

14. Tseng, R.L., Wu, K.T., Wu, FCh., Juang, RSh: Kinetic studies on the adsorption of phenol, 4-chlorophenol, and 2,4-dichlorophenol from water using activated carbons. J. Environ. Manage. 91(11), 2208-2214 (2010)

15. Damjanović, L., Rakić, V., Rac, V., Stosić, D., Auroux, A.: The investigation of phenol removal from aqueous solutions by zeolites as solid adsorbents. J. Hazard. Mater. 184, 477-484 (2010)

16. Froehner, S., Martins, R.F., Furukawa, W., Errera, M.R.: Water remediation by adsorption of phenol onto hydrophobic modified clay. Water Air Soil Poll. 199, 107-113 (2009)

17. Zhou, Sh, Zhang, Ch., Hu, X., Wang, Y., Xu, R., Xia, Ch., Zhang, $\mathrm{H}$., Song, Zh: Catalytic wet peroxide oxidation of 4-chlorophenol over Al-Fe-, Al-Cu-, and Al-Fe-Cu-pillared clays: Sensitivity, kinetics and mechanism. Appl. Clay Sci. 95, 275-283 (2014)

18. Zhou, L.C., Meng, X.G., Fu, J.W., Yang, Y.C., Yang, P., Mi, C.: Highly efficient adsorption of chlorophenols onto chemically modified chitosan. Appl. Surf. Sci. 292, 735-741 (2014)

19. Zhou, L.C., Meng, X.G., LI, J.M., Hu, W., Liu, B.: Kinetics and thermodynamics of adsorption of chlorophenols onto $\beta$-cyclodextrin modified chitosan. Acta Phys. Chim. Sin. 28(07), 1615-1622 (2012)

20. Dabrowski, A., Podkoscielny, P., Hubicki, Z., Barczak, M.: Adsorption of phenolic compounds by activated carbon-a critical review. Chemosphere 58, 1049-1070 (2005)

21. Al-Harahsheh, M., Shawabkeh, R., Al-Harahsheh, A., Tarawneh, K., Batiha, M.: Surface modification and characterization of Jordanian kaolinite: application for lead removal from aqueous solutions. Appl. Surf. Sci. 255, 8098-8103 (2009) 
22. Anbia, M., Davijani, A.H.: Synthesis of L-Cysteine grafted nanoporous carbon (CMK-3) and its use as a new cadmium sorbent. Chem. Eng. J. 223, 899-907 (2013)

23. Wang, W., Zhang, K., Yang, Y., Liu, H., Qiao, Z., Luo, H.: Synthesis of mesoporous $\mathrm{Al}_{2} \mathrm{O}_{3}$ with large surface area and large pore diameter by improved precipitation method. Micropor. Mesopor. Mater. 193, 47-53 (2014)

24. Goscianska, J., Marciniak, M., Pietrzak, R.: Mesoporous carbons modified with lanthanum(III) chloride for methyl orange adsorption. Chem. Eng. J. 247, 258-264 (2014)

25. Anbia, M., Rofouei, M.K., Husain, S.W.: Synthesis of mesoporous lanthanum phosphate and its use as a novel sorbent. Chin. J. Chem. 24, 1026-1030 (2006)

26. Kresge, C.T., Leonowicz, M.E., Roth, W.J., Vartuli, J.C., Beck, J.S.: Ordered mesoporous molecular sieves synthesized by a liquid-crystal template mechanism. Nature 359, 710-712 (1992)

27. Beck, J.S., Vartuli, J.C., Roth, W.J., Leonowicz, M.E., Kresge, C.T., Schmitt, K.D., Chu, C.T.W., Olson, D.H., Sheppard, E.W., McCullen, S.B., Higgins, J.B., Schlenker, J.L.: A new family of mesoporous molecular sieves prepared with liquid crystal templates. J. Am. Chem. Soc. 114, 10834-10843 (1992)

28. Anbia, M., Moradi, S.E.: Removal of naphthalene from petrochemical wastewater streams using carbon nanoporous adsorbent. Appl. Surf. Sci. 255, 5041-5047 (2009)

29. Wang, G., Liu, G., Xu, M., Yang, Z., Liu, Z., Liu, Y., Chen, S., Wang, L.: Ti-MCM-41 supported phosphotungstic acid: an effective and environmentally benign catalyst for epoxidation of styrene. Appl. Surf. Sci. 255, 2632-2640 (2008)

30. Liu, Y., Chen, J., Yao, J., Lu, Y., Zhang, L., Liu, X.: Preparation and properties of sulfonated carbon-silica composites from sucrose dispersed on MCM-48. Chem. Eng. J. 148, 201-206 (2009)

31. Zhang, X., Wu, W., Wang, J., Tian, X.: Direct synthesis and characterization of highly ordered functional mesoporous silica thin films with high amino-groups content. Appl. Surf. Sci. 254, 2893-2899 (2008)

32. Lam, K.F., Fong, C.M., Yeung, K.L., Mckay, G.: Selective adsorption of gold from complex mixtures using mesoporous adsorbents. Chem. Eng. J. 145, 185-195 (2008)

33. Wang, X., Sun, T., Yang, J., Zhao, L., Jia, J.: Low-temperature $\mathrm{H} 2 \mathrm{~S}$ removal from gas streams with SBA-15 supported $\mathrm{ZnO}$ nanoparticles. Chem. Eng. J. 142, 48-55 (2008)

34. Bencs, L., Ravindra, K., Grieken, R.V.: Methods for the determination of platinum group elements originating from the abrasion of automotive catalytic converters. Spectrochim. Acta B. 58, 1723-1733 (2003)

35. Yang, W., Ding, P., Zhou, L., Yu, J., Chen, X., Jiao, F.: Preparation of diamine modified mesoporous silica on multi-walled carbon nanotubes for the adsorption of heavy metals in aqueous solution. Appl. Surf. Sci. 282, 38-45 (2013)

36. Zolfaghari, G., Esmaili-Sari, A., Anbia, M., Younesi, H., Ghasemian, M.B.: A zinc oxide-coated nanoporous carbon adsorbent for lead removal from water: optimization, equilibrium modeling, and kinetics studies. Int. J. Environ. Sci. Technol. 10, 325-340 (2013)

37. Anbia, M., Moradi, S.E.: Adsorption of naphthalene-derived compounds from water by chemically oxidized nanoporous carbon. Chem. Eng. J. 148, 452-458 (2009)
38. Shao, Y., Wang, L., Zhang, J., Anpo, M.: Synthesis of hydrothermally stable and long range ordered Ce-MCM-48 and FeMCM-48 materials. Micropor. Mesopor. Mater. 109, 20835-20841 (2005)

39. Kruk, M., Jaroniec, M.: Gas adsorption characterization of ordered organic-inorganic nanocomposite materials. Chem. Mater. 13, 3169-3183 (2001)

40. Kruk, M., Jaroniec, M., Kim, J.M., Ryoo, R.: Characterization of highly ordered MCM-41 silicas Using X-ray diffraction and nitrogen adsorption. Langmuir 15, 5279-5284 (1999)

41. Alfredsson, V., Anderson, M.W.: Anderson, structure of MCM48 revealed by transmission electron microscopy. Chem. Mater. 8, 1141-1146 (1996)

42. Xu, J., Lv, X., Li, J., Li, Y., Shen, L., Zhou, H., Xu, X.: Simultaneous adsorption and dechlorination of 2,4-dichlorophenol by $\mathrm{Pd} / \mathrm{Fe}$ nanoparticles with multi-walled carbon nanotube support. J. Hazard. Mater. 225-226, 36-45 (2012)

43. Andini, S., Cioffi, R., Colangelo, F., Montagnaro, F., Santoro, L.: Adsorption of chlorophenol, chloroaniline and methylene blue on fuel oil fly ash. J. Hazard. Mater. 157, 599-604 (2008)

44. Shaarani, F.W., Hameed, B.H.: Ammonia-modified activated carbon for the adsorption of 2,4-dichlorophenol. Chem. Eng. J. 169, 180-185 (2011)

45. Shaarani, F.W., Hameed, B.H.: Batch adsorption of 2,4-dichlorophenol onto activated carbon derived from agricultural waste. Desalination 255, 159-164 (2010)

46. Wang, L., Zhang, J., Zhao, R., Zhang, Ch., Li, C., Li, Y.: Adsorption of 2,4-dichlorophenol on Mn-modified activated carbon prepared from Polygonum orientale Linn. Desalination 266, 175-181 (2011)

47. Raoov, M., Mohamad, Sh, Abas, M.R.: Removal of 2,4-dichlorophenol using cyclodextrin-ionic liquid polymer as a macroporous material: characterization, adsorption isotherm, kinetic study, thermodynamics. J. Hazard. Mater. 263, 501-516 (2013)

48. Laszlo, K.: Adsorption from aqueous phenol and aniline solutions on activated carbons with different surface chemistry. Colloids Surf. A 265, 32-39 (2005)

49. Liu, X., Pinto, N.G.: Ideal adsorbed phase model for adsorption of phenolic compounds on activated carbon. Carbon 35, 1387-1397 (1997)

50. Caetano, M., Valderrama, C., Farran, A., Cortina, J.L.: Phenol removal from aqueous solution by adsorption and ion exchange mechanisms onto polymeric resins. J. Colloid Interface Sci. 338, 402-409 (2009)

51. Langmuir, I.: The constitution and fundamental properties of solids and liquids. J. Am. Chem. Soc. 38(11), 2221-2295 (1916)

52. Bilgili, : Adsorption of 4-chlorophenol from aqueous solutions by xad-4 resin: isotherm, kinetic, and thermodynamic analysis. J. Hazard. Mater. B 137, 157-164 (2006)

53. Freundlich, H.M.F.: Over the adsorption in solution. J. Phys. Chem. 57, 385-470 (1906)

54. Alhamed, Y.A.: Adsorption kinetics and performance of packed bed adsorber for phenol removal using activated carbon from dates' stones. J. Hazard. Mater. 170, 763-770 (2009)

55. Ho, Y.S., McKay, G.: Pseudo-second order model for sorption processes. Process Biochem. 34(5), 451-465 (1999) 